\title{
Multi-objective Pareto and GAs nonlinear optimization approach for flyback transformer
}

\author{
Sobhi Barg ${ }^{1}$ (D) $\cdot$ Kent Bertilsson ${ }^{1}$
}

Received: 16 February 2019 / Accepted: 11 September 2019 / Published online: 25 September 2019

(c) The Author(s) 2019

\begin{abstract}
Design and optimization of high-frequency inductive components is a complex task because of the huge number of variables to manipulate, the strong interdependence and the interaction between variables, the nonlinear variation of some design variables as well as the problem nonlinearity. This paper proposes a multi-objective design methodology of a 200-W flyback transformer in continuous conduction mode using genetic algorithms and Pareto optimality concept. The objective is to minimize loss, volume and cost of the transformer. Design variables such as the duty cycle, the winding configuration and the core shape, which have great effects on the former objectives but were neglected in previous works, are considered in this paper. The optimization is performed in discrete research space at different switching frequencies. In total, 24 magnetic materials, 6 core shapes and 2 winding configurations are considered in the database. Accurate volume and cost models are also developed to deal with the optimization in the discrete research space. The bi-objective (loss-volume) and tri-objective (loss-volume-cost) optimization results are presented, and the variations of the design variables are analyzed for the case of $60 \mathrm{kHz}$. An example of a design $(30 \mathrm{kHz})$ is experimentally verified. The registered efficiency is $88 \%$ at full load.
\end{abstract}

Keywords Genetic algorithms · NSGAII · Pareto front · Flyback converter · Transformer · Core loss · Winding loss

List of symbols
$V_{\mathrm{in}}, V_{\text {out, }}, P_{\mathrm{in}}, P_{\text {out }}$
$P_{\mathrm{t}}, P_{\mathrm{c}}, P_{\mathrm{w}}$
$D, l_{\mathrm{g}}, J$
$V_{\mathrm{p}}, V_{\mathrm{s}}, I_{\mathrm{p}}, I_{\mathrm{s}}$
$N_{\mathrm{lp}}, N_{\mathrm{ls}}, N_{\mathrm{tp}}, N_{\mathrm{ts}}$
$C_{\mathrm{c}}, W_{\mathrm{c}}$
$d_{\mathrm{p}}, d_{\mathrm{s}}$
$l_{\mathrm{c}}, l_{\mathrm{m}}$
$I_{\mathrm{pmax}}, I_{\mathrm{smax}}$
$I_{\mathrm{pavg}}, I_{\mathrm{savg}}$
$I_{\mathrm{pr}}, I_{\mathrm{sr}}$
$R_{\mathrm{dcp}}, R_{\mathrm{dcs}}$
$F_{\mathrm{r}}$, Ac
$x$

Sobhi Barg

Sobhi.Barg@miun.se

1 Mid Sweden University, Sundsvall, Sweden current currents currents

$$
\begin{aligned}
& L_{\mathrm{p}}, L_{\mathrm{s}} \\
& B_{\mathrm{ac}}, B_{\max } \\
& N_{\mathrm{p}}, N_{\mathrm{s}} \\
& V_{\mathrm{tr}}, V_{\mathrm{c}}, V_{\mathrm{w}} \\
& \mu_{0}, \mu_{\mathrm{r}} \\
& I_{\mathrm{prms}}, I_{\mathrm{srms}} \\
& f, f_{\mathrm{u}}
\end{aligned}
$$$$
\text { Duty cycle, air gap, current density }
$$$$
\text { Primary and secondary voltage and }
$$

Primary and secondary number of layers and number of turns per layer Core cost and winding configuration Primary and secondary diameters Mean core length and mean turn length Primary and secondary maximum Primary and secondary average Primary and secondary currents ripple Primary and secondary DC resistance Ac-to-dc resistance ratio, core section Diameter-to-skin depth ratio
Primary and secondary inductance Swing and maximum flux density Primary and secondary number of turns volumes Vacuum and relative permeability Primary and secondary RMS currents Frequency and winding filling factor

\section{Introduction}

Flyback converter is widely used in low-power applications such as laptop and mobile chargers. It has several advantages compared to other topologies, especially for low-power applications. On the other side, this topology presents one major inconvenient which is its limited power capability. The converter is only suitable for low power $(<150 \mathrm{~W})$, and its efficiency degrades as the power increases. This is due to the conflict in the inductance design requirements. From one side, the inductance needs to be increased in order to allow more power storage capability during the on-time, and from the other side, it needs to be decreased because it is inversely 
proportional to the output power [1-6]. Several parameters and interdependent variables contribute in the design of the flyback transformer. The conflict in the design of the transformer inductance makes the optimization process a complex task which needs advanced design and optimization techniques to improve its performance.

Classical design techniques of inductive components are mainly the area product method and the core geometry coefficient $[6,7]$. Both design approaches do not consider the nonlinearity of the design variables or/and the nonlinearity of the complete problem. Moreover, the variables are very dependent on each other which make the problem impossible to be solved accurately using these methods. Some other techniques were presented to optimize the magnetic devices by determining the optimum magnetic flux density; however, they do not solve the nonlinearity issue [8-10]. The limitations of these methods are discussed more deeply in Sect. 2.1.

The consideration of more than one objective in the optimization transforms the problem to a multi-objective problem which cannot be solved by the previous presented techniques. Some methods like the weighted sum method and the Min/Max method were used for this kind of problems [11]. However, they can only deal with convex and continuous functions which is not the case of the inductive components design problem.

Genetic algorithms and Pareto optimality concept starts to be a common solution in the design of electromagnetic devices in the last decade [11-22]. The main feature of the GAs is their capability to handle numerous optimization variables and objective functions without losing accuracy in the convergence to the optimum Pareto front. They are also very effective in solving problems with discontinuous variables, concave and convex, linear and nonlinear, constrained and non-constrained objective functions. Additionally, GAs allow also reducing the design time and eventually the cost. All the previous advantages make of the GAs a good candidate for the multi-objective optimization of the inductive components.

From another side, the convergence to the optimum set of solutions doesn't only depend on the performance of the optimization algorithms but more importantly on the problem formulation. This later includes the selection of the design variables, the design equations, the design constraints and the sequences between them. As an example, in some types of nonlinear problems, one variable or more can be at the same time an objective function and a design variable or it can also be a constraint. Few works were achieved to optimize the inductive components for power electronics such as [13] and [14]; however, no one of them addressed these issues. The goal of this paper is to deal with this problem. Particularly in this work, some crucial variables such as the duty cycle, which has a great effect on the transformer loss, the efficiency, the magnetic material and the winding configurations, are considered as main design variables. Finally, to improve the design objectives, reliable and accurate models of the objective functions, the design constraints and the intermediate design functions, such as core loss, winding loss and leakage inductance, are developed.

\subsection{Research contributions}

The main contributions of this work are:

1. To develop a multi-objective optimization approach to design a flyback transformer in continuous conduction mode using GAs and Pareto optimality concept.

2. To solve the nonlinearity of the design problem resulting from the interdependence between the design variables, the objective functions and the design constraints.

3. To include the effect of some crucial variables in the optimization process such as the duty cycle and the efficiency which are neglected in the previous works.

4. To analyze the variation of the design and optimization variables with respect to the Pareto front for the biobjective (loss-volume) optimization and tri-objective (loss-volume-cost) optimization problems in order to get a clear picture on the variation of these variables with respect to the objective functions.

5. To verify the optimization results of the transformer designed for $30 \mathrm{kHz}$ by experiments and comparison with existing approaches.

6. To give an insightful picture on the state-of-the-art on the design and optimization of inductive components.

This paper is organized as follows. A review of the optimization and design methods of inductive components is presented in the second section. The third section details the multi-objective design and optimization approach. The optimization results are highlighted and analyzed in the fourth section. The experimental verification and comparison with classical methods of a design case are shown in the fifth section. Finally, the advantages of the future works of the proposed design are summarized in the conclusion.

\section{Review of the high-frequency inductive components design and optimization methods}

\subsection{Challenges in the design of HF transformer}

The major challenges faced today by designers of highfrequency transformers are the selection of: the appropriate magnetic material, the suitable core shape, the required core size and the winding configuration. All the former variables 
are generally chosen based on the designer experience to satisfy the design constraints and requirements which can reduce the design efficiency. The selection of the switching frequency and the duty cycle is defined arbitrarily. However, it was shown in the literature that the duty cycle presents a great effect on the core loss and the winding loss [22-32]. The frequency has also an important role in the transformer loss and volume. Thus, the consideration of these variables as main design and optimization variables is crucial. The determination of the number of turns, the calculation of the air gap and some other intermediate functions is derived from the relationships between the inductance reluctance model, the energy storage equation and Faraday's and Ampere's laws. These variables have nonlinear relationships between each other. Furthermore, the design of high-frequency transformers needs to take into consideration some constraints such as the leakage inductance and the temperature rise. In general, there is a huge interdependence and interaction between the design variables, the intermediate design functions, the design constraints and the objective functions which makes the problem very complex to be solved.

In a given design problem, one combination or more of the previous discussed design variables can be the optimum set of solutions for the objective functions such as the efficiency, the cost and the volume. In the following, the existing methods are analyzed and their limitations to solve the former issues are figured out. The existing methods can be classified into two categories: single-objective methods and multi-objective methods.

\subsection{Single-objective methods}

The area product method was early developed to select the suitable magnetic core for a given application [6, 7, 33]. It is a geometry dimensional factor of magnetic cores which has an equivalent term of electrical variables of the power converter. The equivalent term depends on the maximum magnetic flux density. The geometry term is the product of the core window area and the core cross section. In the literature, there are several forms of the area product. Some correction factors are adopted by industrials in order to meet the design requirements [34-36]. For example, author in [34, 35 ] has proposed that the volume of the flyback transformer is twice the one for forward. This correction factor is used because the flyback transformer needs to store energy during the on-time. In [2], a monogram of the area product as a function of the stored energy is given in [36], and the area product was expressed as a function of the magnetizing inductance to take into consideration the effect of the DC current and the stored energy.

The first drawback of the area product (AP) method is that it includes the filling factor which is an unknown and usually estimated to 0.3 or 0.4 . Secondly, the product between the core section and the window area doesn't give a real picture and an accurate characterization of the core shape. In other terms, the area product does not take into account the core shape effect on the design because two different core shapes can have the same AP. Furthermore, the area product method allows only getting an idea about the required core size; however, all the remaining variables, such as the material and the winding configuration, are chosen by the designer using his own experience. In addition to that, this method does not minimize the transformer loss because it doesn't include the eddy currents effect at high frequency.

The core geometry coefficient method is also a geometry dimensional factor. The expression of the core geometry coefficient is derived from the formula of the optimum magnetic flux density that yields to minimum transformer/ inductance loss. It includes the core length in addition to the core window and the core cross section which can improve the accuracy in the selection of the suitable magnetic core. It also includes the Steinmetz parameters, characterizing the core loss of the magnetic materials. This feature offers the possibility to consider the effect of the magnetic material loss in the design process, and therefore the selection of the best material becomes achievable [37].

Although the core geometry coefficient offers better accuracy in the selection of the suitable magnetic core than the area product, it still presents major limitations which are summarized as follows: (1) the method is a single-objective design approach used to improve the efficiency and not the cost or the volume, (2) the method is only suitable at fixed frequency and fixed duty cycle, and (3) the method needs an iterative approach to include the effect of the core shape because magnetic core with different shapes might have the same core geometry.

Hurley developed an improved expression of the equivalent term of the area product to include high-frequency effects such as the skin and the proximity effects as well as the temperature effect. This was achieved by calculating the optimum magnetic flux density instead of using the maximum magnetic flux density $[9,10]$.

A similar approach based on the determination of the optimum magnetic flux density was presented by Petkov but without consideration of the high-frequency effects [8].

In [38], the weighted efficiency method was applied to optimize the flyback inverter, including the transformer component, for photovoltaic applications. The optimization of the weighted function was solved by the differential evolution method.

\subsection{Multi-objective methods}

In the former design approaches, the efficiency is the only objective to deal with as it is the major concern of 
the designer. In the last decade, designers are much more interested to optimize, not only the converter efficiency, but also the cost and the volume in order to meet the standards and clients requirements. This is called a multi-objective optimization problem. Genetic algorithms are powerful optimization methods to solve this kind of problems. Pareto front is also one insightful and effective tool to represent the optimum solution in the objectives space or variables space. Using Pareto optimality concept, the decision maker can move along the Pareto front to select one of the optimal solutions that meets the required needs. It is also possible to know the evolution of the optimization variables and any intermediate function with respect to Pareto front. Hence, the effect of every variable can be well understood and analyzed. In fact, using GAs and Pareto concept of optimality, we can get a clear picture of the full problem in the objective space and the intrinsic variation of the design variables can be seen at any optimal operating point [11, 19-21]. In [12], GAs was used to achieve the best tradeoff between volume and loss of PWM inverter output filters. In [13], the loss and weight optimization of medium frequency transformers was performed using genetic algorithms (NSGAII). The main limitation of this work is that the capability of the GAs to solve nonlinear problems is not fully utilized. As an example, in [13], the value of the required inductance was initialized in the design of LLC and DAB converter. GAs was applied to determine the optimum set of the variables given by the inductance reluctance model independently of the converter operation constraints. However, to be more accurate, the value of the required inductance depends on several other variables, depending on the converter topology, such as the duty cycle, the frequency and the efficiency. In a similar way in [14], the magnetizing inductance was considered as a fixed parameter for LLC converter which is not enough accurate design approach.

Generally speaking, in the previous discussed works, the dependency of required inductance on the converter requirements (efficiency, duty cycle, frequency, etc.) was neglected and this can reduce the design accuracy. Another important issue which was not clearly explained and formulated in previous work is the relationship between the different optimization variables, the objective functions and the design constraints which all contribute in the nonlinearity of the design problem. Additionally, the models of the objective functions present lack of accuracy such as the negligence of the temperature effect on the core loss.

In [15], two kinds of evolutionary algorithms (GA and PSO) have been tested to optimize the volume and the mass of EI and UI core inductor, respectively. A continuation of the work presented in [15] is exhibited in [16]. The single optimization (volume) and the bi-objective optimization (loss vs. volume and loss vs. cost) of the EI inductor are performed. The tri-objective optimization is also presented by optimizing the cost and the volume constrained to the objective function loss. The single-objective optimization is presented with continuous and discrete variables. GOSET optimization tool, developed by authors in [17, 18], was used to achieve the optimization process. It was shown that GOSET tool allows achieving better minimization with discrete variables. The structure of GOSET is similar to NSGAII but with more optional function that improves its performance. In [19], a multi-objective optimization approach was presented to minimize the losses, the weight and the volume of power inductors for three-phase high power density inverter.

\subsection{0-W flyback converter design complexity}

Designing a $200-\mathrm{W}$ flyback converter is very complicated due to the reasons discussed previously. In the literature, there are few attempts done to realize a flyback converter at this power level. The only industrial 200-W flyback converter was designed by Texas Instruments. The adopted solution consists in using two interleaved transformers with an inductance of $500 \mu \mathrm{H}$ each, and the switching frequency is $100 \mathrm{kHz}$. The value of the inductance reflects the significant volume of the used transformers [39]. Another company developed a $140-\mathrm{W}$ flyback converter, but it can supply a maximum power of $200 \mathrm{~W}$ [40]. The inductance of the transformer is $300 \mu \mathrm{H}$. Another study in [41] showed the design of a 180-W flyback converter using a regenerative snubber circuit concept. The magnetizing inductance is $102 \mu \mathrm{H}$, and the switching frequency is $80 \mathrm{kHz}$.

In all the previous designs, the use of a big inductance is necessary to reach the 200-W output. In the following, GAs and Pareto front optimality concept is used to optimize the 200-W flyback transformer.

\section{Design approach}

\subsection{Problem description}

The objective is to perform the bi-objective (loss-volume) and tri-objective (loss-volume-cost) optimization of highfrequency transformer for a $200-\mathrm{W}$ flyback converter. The characteristics of the converter are summarized in Table 1.

Table 1 Converter characteristics

\begin{tabular}{ll}
\hline Output voltage & $120 \mathrm{~V}$ \\
Input voltage & $48 \mathrm{~V}$ \\
Output power & $200 \mathrm{~W}$ \\
Maximum tem- & $60{ }^{\circ} \mathrm{C}$ \\
perature rise & \\
Frequency & $10-20-30-$ \\
& $40-50-$ \\
& $60 \mathrm{kHz}$ \\
\hline
\end{tabular}


Several variables and constraints contribute in the design of flyback transformer. As per our knowledge, still there is no study solving the optimization of this magnetic problem with consideration of all variables due to the issues discussed in Sect. 2. Using the advantages of GAs, the optimization of the flyback transformer with consideration of all the design variables becomes possible. All the data of the magnetic cores and magnetic materials are summarized in Tables 5, 6 and 7 .

\subsection{Core loss prediction}

Several empirical models have been developed to calculate magnetic core loss of high-frequency inductive components used in switching power supplies. These models, which are the modified Steinmetz equation, the generalized Steinmetz equation (GSE), the improved GSE and the improved ${ }^{2}$ GSE, are derived from the Steinmetz equation [23-27]. They present some limitations which are explained in [22]. The model given in [22] [Eq. (1)] solves the limitations of the former models. Its main features are: high accuracy especially at low duty cycle, compact, reliable and easy to apply.

$\left\langle P_{\mathrm{c}}\right\rangle=\frac{\pi}{4}\left[\begin{array}{c}k_{1} D\left(\frac{f}{2 D}\right)^{\alpha_{1}}\left(B_{\mathrm{ac}}\right)^{\beta_{1}} \\ +k_{2}(1-D)\left(\frac{f}{2(1-D)}\right)^{\alpha_{2}}\left(B_{\mathrm{ac}}\right)^{\beta_{2}}\end{array}\right] V_{\mathrm{c}}$

In this work, the Steinmetz parameters are expressed as a function of the frequency in order to improve the reliability of the optimization algorithm [22]. Figure 1 shows how accurately the Steinmetz parameters are derived and the high consistency between the manufacturer data and the developed model for material N27.

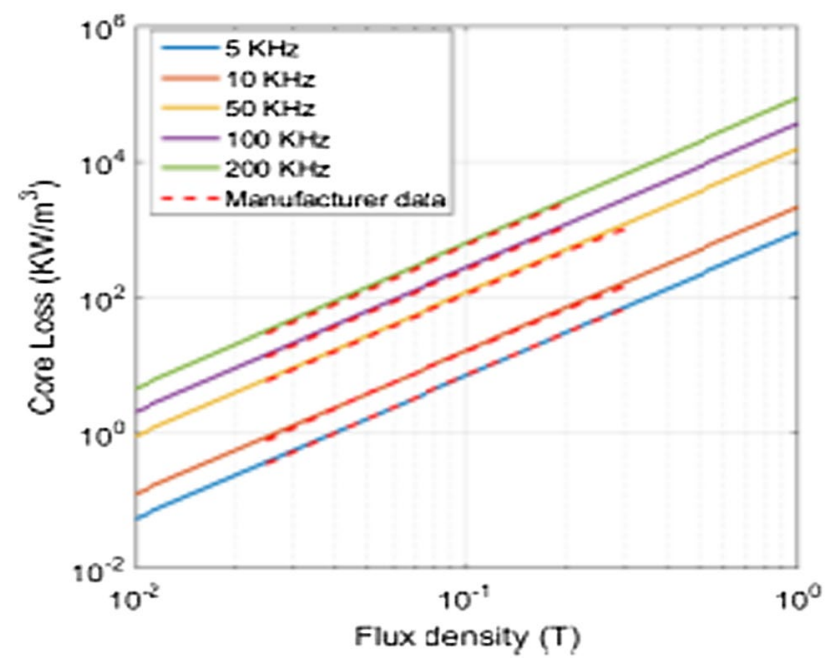

Fig. 1 Modeling of core loss curves for N27
To include the effect of the temperature, the following equation was developed using curve fitting technique of the core loss given in manufacturer's catalogs. It is multiplied to Eq. (1):

$f(T)=a_{0} T^{2}+a_{1} T+a_{2}$

\subsection{Winding loss}

At high frequency, the skin effect and the proximity effect are significant and their impact on the AC resistance is very huge. In the literature, there are various models to account the effect of these phenomena such as Dowel's formula and Ferreira's formula [28, 29]. Dowell's formula has shown a good accuracy and consistency with measurements [30-32]. For this reason, it is applied in our design. The winding loss can be expressed as follows:

$P_{\mathrm{w}}=R_{\mathrm{dcp}} F_{\mathrm{rp}} I_{\mathrm{prms}}^{2}+R_{\mathrm{dcs}} F_{\mathrm{rs}} I_{\mathrm{srms}}^{2}$

$F_{\mathrm{r}}=x\left[\frac{e^{2 x}-e^{-2 x}+2 \sin 2 x}{e^{2 x}-e^{-2 x}-2 \cos 2 x}+\frac{2\left(N^{2}-1\right)}{3} \frac{e^{2 x}-e^{-2 x}-2 \sin 2 x}{e^{2 x}-e^{-2 x}+2 \cos 2 x}\right]$

\subsection{Volume modeling}

The volume models presented in the literature are not enough accurate and cannot be applied for all geometries. The winding configuration and the core reference are two optimization variables as it is given in Sect. 3.6. For that reason, a volume model was developed for each configuration and each core geometry. In the following, we detail the volume model using EE core with split winding (see Fig. 2). The objective is that the developed model should be expressed as a function of the optimization variables to improve the algorithm reliability.

$V_{\mathrm{c}}=L_{\mathrm{c}} A_{\mathrm{c}}$

$A_{\mathrm{c}}=D F$

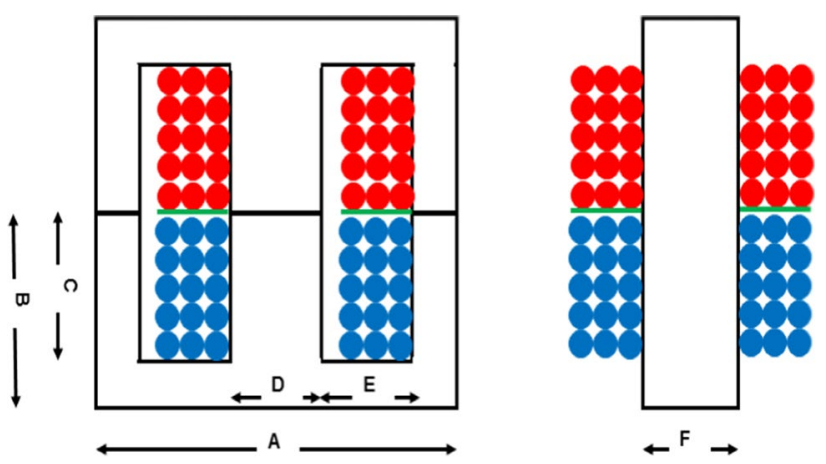

Fig. 2 Core type EE with split winding configuration 
The primary winding volume is equal to:

$$
V_{\mathrm{wp}}=2 N_{\mathrm{tp}} d_{\mathrm{p}}^{2}\left(F+D+2 N_{\mathrm{lp}} d_{\mathrm{p}}\right)
$$

Similarly, the secondary winding is calculated.

\subsection{Transformer cost modeling}

The cost model is derived using curve fitting technique from the data in $[39,42]$. It is a function of the volume, the magnetic material and the geometry.

$C_{\mathrm{c}}=k\left(a V_{\mathrm{c}}^{\mathrm{b}}+c\right)$

Parameter k represents the geometry cost effect, and a, b and $\mathrm{c}$ are parameters depending on the magnetic material.

\subsection{Problem formulation}

The objective of this work is to minimize the loss, the volume and the cost of the flyback transformer. Their models are given in the previous subsections. In order to achieve an accurate design, a good understanding of the design equations as well as the dependency and interaction between the optimization variables, the design constraints and objective functions is mandatory.

The full design equations of the flyback converter are given in Eqs. (9-13). As it can be seen in Eq. (10), the efficiency is a design variable. Simultaneously, it represents the first objective function as it reflects the total loss. This later appears also in Eq. (19) as a design constraint of the temperature rise. This clearly represents one aspect of nonlinear problem. In order to deal with this issue, an optimization variable referred to as "effective efficiency" is generated as shown in Table 2. Then, by imposing an equality constraint between the efficiency (objective function) and the effective efficiency (variable), the problem can be solved. The same idea is performed for

Table 2 Design space for the discrete research spaces

\begin{tabular}{llll}
\hline Variable & Unit & Type & Interval \\
\hline Magnetic material & $\mathrm{U}$ & Integer & {$[1-24]$} \\
Duty cycle & - & Integer & {$[1-72]$} \\
Core reference & $\mathrm{U}$ & Integer & {$[1-n]$} \\
$W_{\mathrm{c}}$ & $\mathrm{U}$ & Integer & {$[1-2]$} \\
$N_{\mathrm{p}}$ & $\mathrm{U}$ & Integer & {$[1-100]$} \\
$N_{\mathrm{s}}$ & $\mathrm{U}$ & Integer & {$[1-100]$} \\
$d_{\mathrm{p}}$ & $\mathrm{U}$ & Integer & {$[1-60]$} \\
$d_{\mathrm{s}}$ & $\mathrm{U}$ & Integer & {$[1-60]$} \\
$l_{\mathrm{g}}$ & $\mathrm{M}$ & Real & {$[1 \mathrm{e}-4,4 \mathrm{e}-3]$} \\
$\eta_{\mathrm{i}}$ & - & Real & {$[0.95-0.99]$} \\
\hline
\end{tabular}

the air gap which has an effect on the inductance and the core saturation as given in Eqs. (9 and 16).

GOSET optimization tool, discussed in Sect. 2.3, is used in our work. The optimization flowchart is given in Fig. 3 . For one iteration, a set of variables, given in Table 2, is randomly chosen by the algorithm and applied for the different calculation steps. The calculation phase includes the design equations, the design constraint, the objective functions and the intermediate functions. Solutions which do not satisfy the design constraints are discarded; however, those which fulfill the requirements are ranked to form the Pareto front of the $i$ th iteration. The process is repeated until the Pareto front is reached. The needed number of iteration is defined by the user.

\subsubsection{Design equations of the transformer}

The design equations of the flyback transformer are summarized below.

$L_{\mathrm{p}}=\frac{\mu_{0} \mu_{\mathrm{r}} N_{\mathrm{p}}^{2} A_{c}}{\left(l_{\mathrm{c}}+l_{\mathrm{g}} \mu_{\mathrm{r}}\right)} ;$

$L_{\mathrm{s}}=\frac{\mu_{0} \mu_{\mathrm{r}} N_{\mathrm{s}}^{2} A_{\mathrm{c}}}{\left(l_{\mathrm{c}}+l_{\mathrm{g}} \mu_{\mathrm{r}}\right)}$

$P_{\text {in }}=\frac{P_{\text {out }}}{\eta_{\text {i }}}$

$I_{s}=\frac{P_{\mathrm{out}}}{V_{\mathrm{out}}} \quad I_{\mathrm{savg}}=\frac{I_{\mathrm{s}}}{(1-D)} ; \quad I_{\mathrm{srms}}=\frac{I_{\mathrm{s}}}{\sqrt{(1-D)}}$

$I_{\text {sr }}=\frac{V_{\text {out }}(1-D)}{L_{\mathrm{s}} f} ; \quad I_{\text {smax }}=\frac{I_{\text {sr }}}{2}+I_{\text {savg }}$

$I_{\mathrm{p}}=\frac{P_{\text {in }}}{V_{\text {in }}} ;$

$I_{\text {pavg }}=\frac{I_{\mathrm{p}}}{D}$

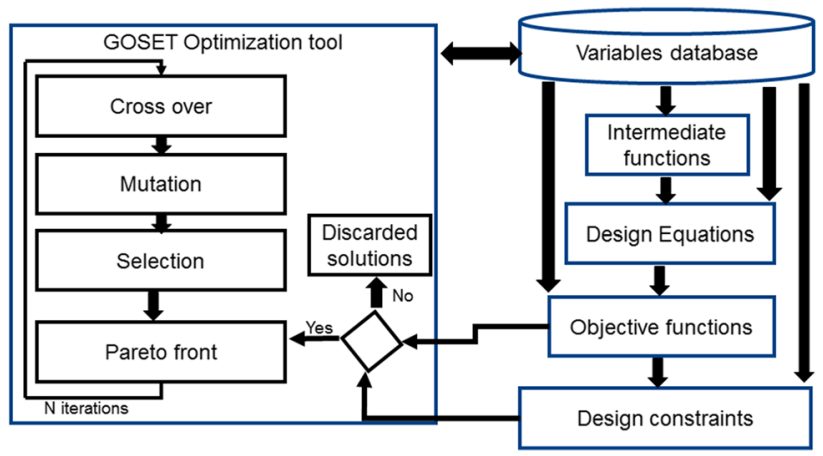

Fig. 3 Flowchart of the optimization tool 


$$
\begin{aligned}
& I_{\mathrm{pr}}=\frac{V_{\mathrm{in}} D}{L_{\mathrm{p}} f} \\
& I_{\mathrm{prms}}=\frac{I_{\mathrm{p}}}{\sqrt{D}} ; \\
& I_{\mathrm{pmax}}=\frac{I_{\mathrm{pr}}}{2}+I_{\mathrm{parg}} \\
& B_{\mathrm{ac}}=\frac{V_{\mathrm{in}} D}{f N_{\mathrm{p}} A_{\mathrm{c}}} ; \\
& B_{\max }=\frac{B_{\mathrm{ac}} I_{\mathrm{pmax}}}{I_{\mathrm{pr}}}
\end{aligned}
$$

\subsubsection{Design constraints}

The design constraints are summarized as follows:

- The core saturation, the gain and the air gap are as follows:

$B_{\max } \leq 0.7 B_{\mathrm{s}}$

Gain $=\frac{N_{\mathrm{s}} D}{N_{\mathrm{p}}(1-D)}$

$l_{\mathrm{g}}=\frac{\mu_{0} I_{\mathrm{p} \max }^{2} L_{\mathrm{p}}}{A_{\mathrm{s}} B_{\max }^{2}}-\frac{l_{\mathrm{c}}}{\mu_{\mathrm{r}}}$

- Conductor diameters: They are determined by [31].

$d_{\mathrm{p}}=\sqrt{\frac{I_{\mathrm{pmax}}}{7.2}} ; \quad d_{\mathrm{s}}=\sqrt{\frac{I_{\mathrm{smax}}}{7.2}}$

- The winding area $A_{\mathrm{w}}$ should be capable of allocating the two windings. $f_{\mathrm{u}}$ is equal to 0.4 .

$A_{\mathrm{w}} \geq \frac{\pi\left(N_{\mathrm{p}} d_{\mathrm{p}}^{2}+N_{\mathrm{s}} d_{\mathrm{s}}^{2}\right)}{f_{\mathrm{u}}}$

- Temperature rise $T_{\mathrm{r}}$ :

$T_{\mathrm{r}}=\frac{53\left(P_{\mathrm{c}}+P_{\mathrm{w}}\right)}{V_{\mathrm{c}}^{0.53}} \leq 60^{\circ} \mathrm{C}$

- Currents ripple factor: it should be lower than $r_{\max }$.

$$
I_{\mathrm{pr}} \leq r_{\mathrm{max}} ; \quad I_{\mathrm{sr}} \leq r_{\mathrm{max}} I_{\mathrm{savg}}
$$

- Peak MOSFET voltage: the maximum allowable voltage across the MOSFET time must be lower than $400 \mathrm{~V}$.

- Leakage inductance: it is kept lower than $2 \%$ of the magnetizing inductance. Model presented in [42] is used.

\subsubsection{Optimization variables}

The optimization variables are highlighted in Table 2. They are of two types: integer and real.

\section{Multi-objective optimization in discrete research space}

\subsection{Bi-objective optimization}

The results of the GA-based optimization for different frequencies are shown in Fig. 4. The first important thing that can be noticed is the intersection of the Pareto fronts between each other which shows that the dominance of each one depends on the design region in the volume-loss plan. Using Pareto front, the designer has the ability to select the best switching frequency depending on the requirements in term of loss and volume. Generally, $60 \mathrm{kHz}$ can be considered as the optimum frequency. The second optimum frequency is $50 \mathrm{kHz}$. In the volume region [50-600] $\mathrm{cm}^{3}$, the dominant Pareto front is in the descendant frequency order except around $200 \mathrm{~cm}^{3}$ where $30 \mathrm{kHz}$ dominates $40 \mathrm{kHz}$. The minimum optimum volume that can be achieved is $21 \mathrm{~cm}^{3}$ realized with $60 \mathrm{kHz}$. This volume yields to a total loss of $5.9 \mathrm{~W}$. The minimum total loss is $1.8 \mathrm{~W}$ achievable either with $500 \mathrm{~cm}^{3}$ and $50 \mathrm{kHz}$ or with lower volume and $60 \mathrm{kHz}$.

The best magnetic material that offers minimum loss and minimum volume is $\mathrm{F}$ of type ferrite manufactured by

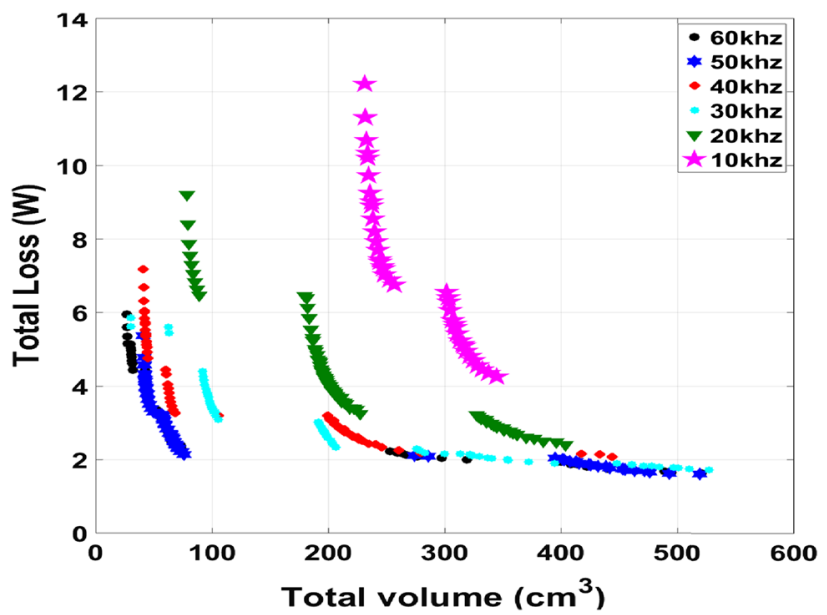

Fig. 4 Pareto fronts of loss versus volume 


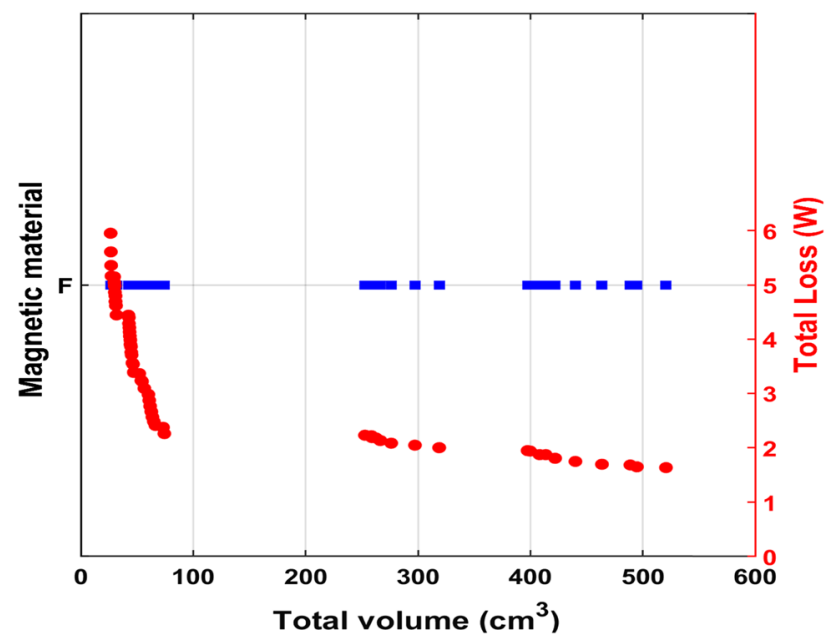

Fig. 5 Magnetic material versus Pareto front

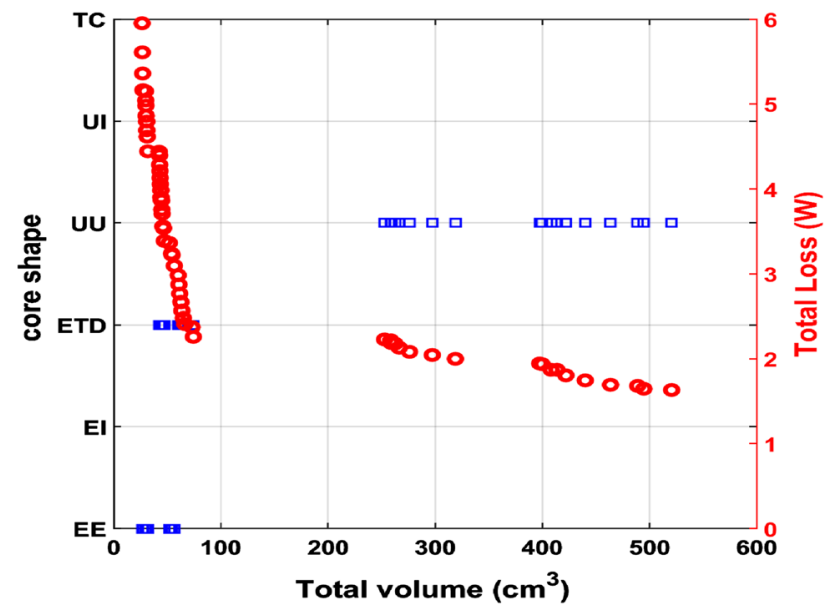

Fig. 6 Core shape versus Pareto front (see Table 7)

Magnetics (Fig. 5). This material has the second highest permeability (3000) among all the ferrite materials in the database, which helps to reduce the magnetizing current and therefore minimize the core loss. It has also the second least specific core loss among all ferrite materials at $60 \mathrm{kHz}$.

EE and ETD shapes are the best geometries for small volume $\left(<100 \mathrm{~cm}^{3}\right)$ and UU and Toroid for big volume (Fig. 6). The choice of UU and Toroid shape for big volume is not because of their performances but because they are the only shapes available with this volume (Table 7).

The diameter of the primary winding increases with the increase in the transformer volume and the decrease in the total loss (Fig. 7).

The results of the tri-objective optimization are depicted in Fig. 8. It can be seen that the $60 \mathrm{kHz}$ keeps almost the best

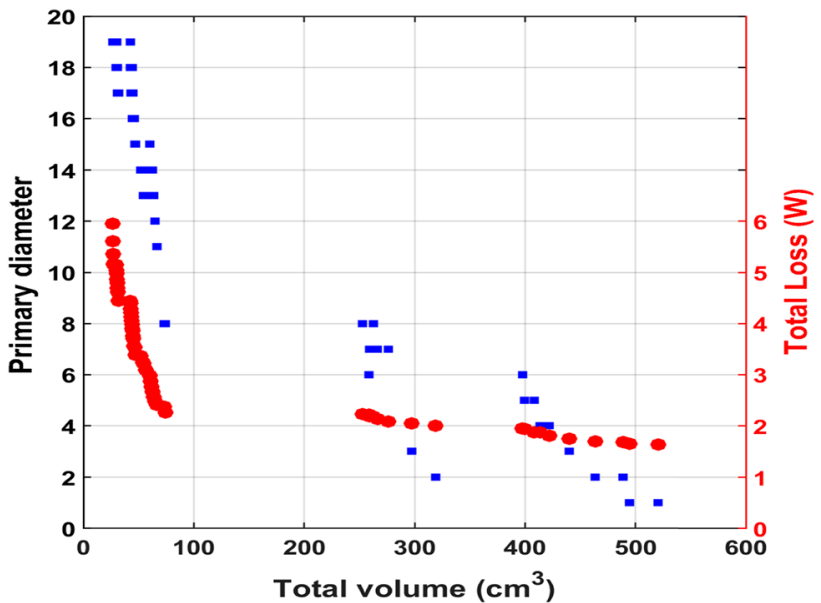

Fig. 7 Primary diameter versus Pareto front

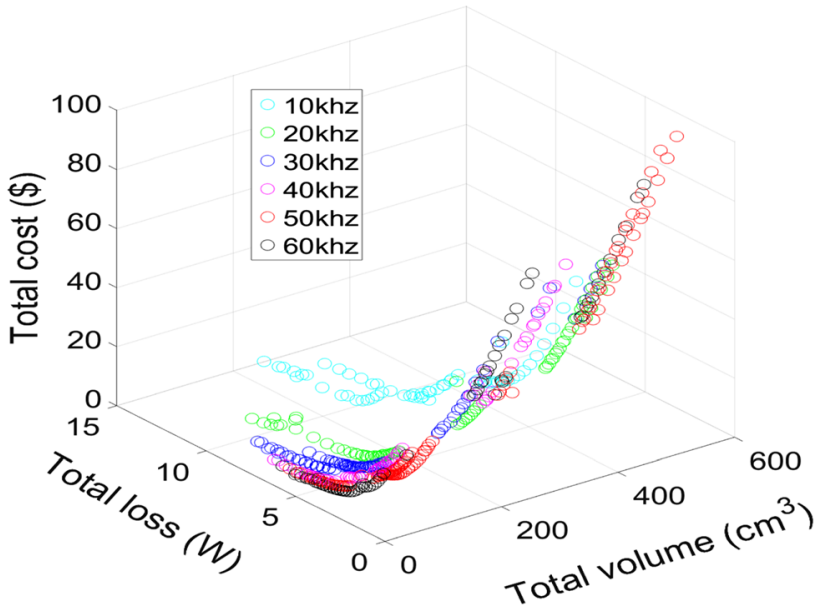

Fig. 8 3D Pareto front of loss-volume and cost

solution. A better way to see the distribution of the Pareto set is to use a $2 \mathrm{D}$ plan for two objective functions, and the third one can be read using color bar tool as given in Fig. 9 for the case of $60 \mathrm{kHz}$. The loss decreases with respect to volume; however, the cost is not (Fig. 10).

Using the normalized Euclidean distance to ideal solution (Eq. 21), the best optimum solution can be determined for the different cases. Their details are shown in Table 3

$d_{\mathrm{is}}=\sqrt{\sum_{i=1}^{n}\left(\frac{f_{i}(x)-f_{i}^{\text {min }}}{f_{i}^{\min }}\right)^{2}}$ 


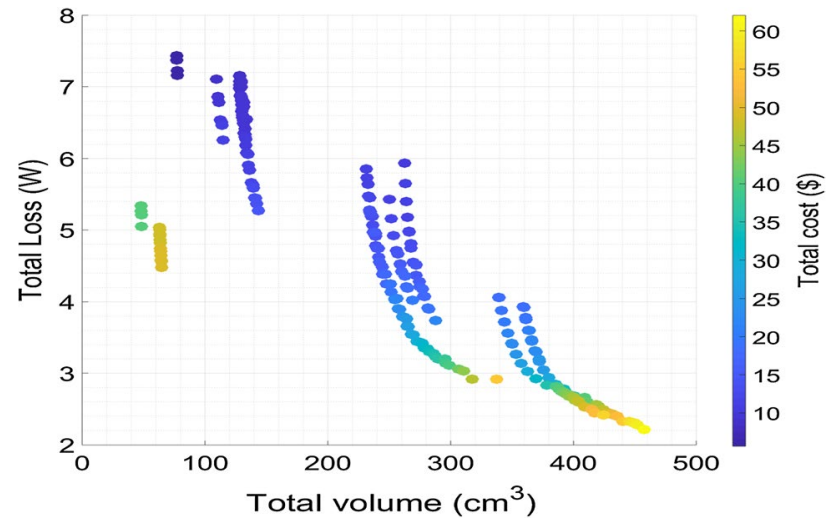

Fig. 9 Pareto front loss-volume-cost for the case of $60 \mathrm{kHz}$

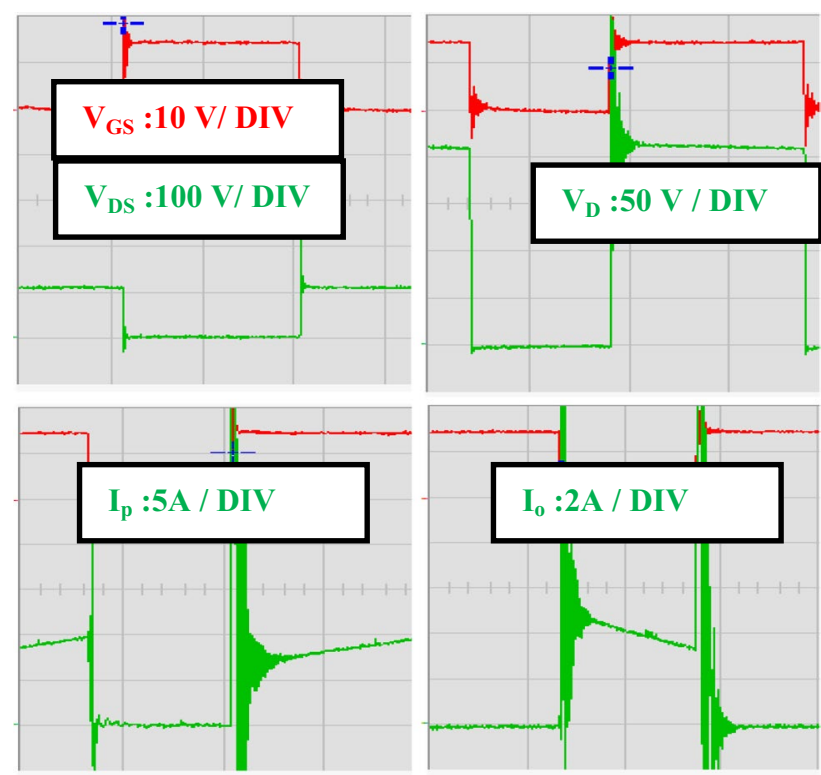

Fig. 10 Experimental flyback converter waveforms at $30 \mathrm{kHz}$ (time division is $6.66 \mu \mathrm{s} / \mathrm{div}$ )

Table 3 Details of the design solutions

\begin{tabular}{lllll}
\hline & $30 \mathrm{kHz}$ & $40 \mathrm{kHz}$ & $50 \mathrm{kHz}$ & $60 \mathrm{kHz}$ \\
\hline Losses $(\mathrm{W})$ & 4.88 & 4.37 & 4.02 & 3.66 \\
Cost $(\$)$ & 5.68 & 3.9764 & 3.96 & 3.32 \\
Volume $\left(\mathrm{cm}^{3}\right)$ & 63.41 & 44.11 & 44.12 & 42.75 \\
Material $/ W_{\mathrm{c}}$ & $\mathrm{F} / 2$ & $\mathrm{~F} / 2$ & $\mathrm{~F} / 2$ & $\mathrm{~F} / 2$ \\
Shape $/$ Ref & $\mathrm{ETD} / 7$ & $\mathrm{ETD} / 6$ & $\mathrm{ETD} / 6$ & $\mathrm{ETD} / 6$ \\
$d_{\mathrm{p}}(\mathrm{mm})$ & 1.82 & 1.8 & 1.82 & 2.05 \\
$d_{\mathrm{s}}(\mathrm{mm})$ & 0.91 & 1.02 & 1.02 & 0.91 \\
$N_{\mathrm{p}} / N_{\mathrm{s}}$ & $23 / 47$ & $24 / 27$ & $17 / 32$ & $9 / 37$ \\
$l_{\mathrm{g}}(\mathrm{mm})$ & 1 & 0.7 & 0.6 & 0.5 \\
\hline
\end{tabular}

\section{Comparison with classical area product method and experimental verification}

The optimum magnetic material that is selected by the optimization algorithm is $\mathrm{F}$ material provided by Magnetics. But, at the time of the experimental implementation, this selected core was not available in the market. For that reason, the optimization process was run a second time and the results show that $\mathrm{R}$ material is the new optimum one. No changes were registered for other variables (core reference, number of turns, duty cycle, etc.).

\subsection{Comparison with the area product methods}

The objective of this section is to compare the outputs of the design case $30 \mathrm{kHz}$ with the outputs of two single-objective design approaches in order to verify the reliability and the accuracy of our results and to get an approximated idea about the efficiency of the design.

The two classical design techniques are the approach of Lloyd from Texas Instruments and the Approach of Sanjaya [34-36]. To give a fair comparison between the different approaches, we have used the same magnetic material which is the optimal one selected by the proposed approach (ferrite F). The duty cycle was fixed to 0.5 for the classical techniques. For the brevity of the paper, we highlight the most important steps of the design in Table 4.

It is clear from Table 4 that the proposed approach yields to better theoretical efficiency than other design techniques. However, Sanjaya approach leads to the worst efficiency resulting from the high number of winding layers. The second approach of Lloyd allows getting the same magnetic core as the one selected by the proposed approach; however, the transformer loss is bigger because of the reduced size of the winding conductors. The first approach of Lloyd has comparable efficiency to our design but with bigger magnetic core.

In comparison with the design solutions given in Sect. 2.3, the inductance of the designed transformer is $233 \mu \mathrm{H}$ at $30 \mathrm{kHz}$ which is much lower than the one designed by Texas and the one proposed by ON Semiconductor.

\subsection{Experimental results}

An IGBT STGFW30V60F is used, and it is controlled using a driver TC4429. A capacitor of $63 \mathrm{~V} 2200 \mathrm{uF}$ is used in the input, and a $400 \mathrm{~V} 47 \mu \mathrm{F}$ for the output filter. The rectifier diode is Mur1560. The sensing resistors in the input and output are $0.1 \Omega, 5 \mathrm{~W}$.

The obtained waveforms of the input and output currents, the IGBT voltage and the diode voltage are shown in Fig. 8 . 
Table 4 Comparison of the design outputs between the proposed approach and the classical techniques $(30 \mathrm{kHz}$ design case)

\begin{tabular}{lllll}
\hline & Proposed approach & \multicolumn{2}{l}{ Lloyd approaches [36] } & $\begin{array}{l}\text { Sanjaya } \\
\text { approach } \\
{[34]}\end{array}$ \\
\cline { 5 - 5 } & & 1st approach & 2nd approach & 216.45 \\
\hline Primary inductance $(\mu \mathrm{H})$ & 233 & 216.45 & & 0.1 \\
Maximum swing flux $(\mathrm{T})$ & 0.1 & 0.1 & & 2.09 \\
Area product $\left(\mathrm{cm}^{4}\right)$ & - & 17.78 & 10.24 & ETD49 \\
Selected core & ETD59 & EE 65 & ETD59 & F \\
Selected material & F & F & & 0.4 \\
Turns ratio & 0.48 & 0.4 & & $38 / 95$ \\
Primary/secondary number of turns & $23 / 47$ & $15 / 38$ & $22 / 55$ & $1.28 / 0.77$ \\
Primary/secondary diameter $(\mathrm{mm})$ & $1.82 / 1.45$ & $1.28 / 0.77$ & & $2 / 2$ \\
Primary/secondary number of layers & $1 / 1$ & $1 / 1$ & & $663 / 2100$ \\
Primary/secondary resistance $(\mathrm{m} \Omega)$ & $81.12 / 327.52$ & $76.54 / 396$ & $112.25 / 574$ & 39 \\
Winding loss $(\mathrm{W})$ & 4.72 & 5.44 & 7.94 & 0.08 \\
Core loss $(\mathrm{W})$ & 0.17 & 0.27 & 0.17 & 39.08 \\
Transformer loss $(\mathrm{W})$ & 4.88 & 5.71 & 8.11 & \\
\hline
\end{tabular}

The efficiency reaches up to $88 \%$ at full load. This efficiency is very acceptable for a $200-\mathrm{W}$ flyback converter operating at $30 \mathrm{kHz}$. The obtained results can be improved by better selection of the switching devices. However, we are limited to use only devices available in the laboratory because it is not the objective of this work to optimize the full converter.

\section{Conclusion}

The paper proposes a multi-objective optimization approach of flyback transformers in discrete research space using GAs. The key conclusions of this paper are summarized as follows:

- The approach solves the limitations of the existing works by considering the effect of the duty cycle and the efficiency as main optimization variables. The approach takes also into account the nonlinear relationships between variables, objective functions and design constraints.

- The proposed approach allows better minimization of the loss and volume in comparison with existing classical methods.
- The approach is very effective as it improves the accuracy of the results compared to other techniques, and it reduces the design time. The optimization needs $30 \mathrm{~min}$ to get the optimum Pareto fronts which can take longer time using classical techniques.

- Results show that the optimal magnetic material and optimal core shape depend on the switching frequency.

- Pareto fronts of the objective functions (loss, cost and volume) are inversely proportional to the switching frequency.

Acknowledgements Open access funding provided by Mid Sweden University.

Open Access This article is distributed under the terms of the Creative Commons Attribution 4.0 International License (http://creativeco mmons.org/licenses/by/4.0/), which permits unrestricted use, distribution, and reproduction in any medium, provided you give appropriate credit to the original author(s) and the source, provide a link to the Creative Commons license, and indicate if changes were made.

\section{Appendix}

See Tables 5, 6 and 7. 
Table 5 Magnetic material characteristics [43-47]

\begin{tabular}{lllcll}
\hline Material & Type & Provider & Permeability & $B_{\mathrm{s}}$ & $T_{\mathrm{c}}\left({ }^{\circ} \mathrm{C}\right)$ \\
\hline N27 & Ferrite & EPCOS & 2000 & 0.5 & 220 \\
N87 & & EPCOS & 2200 & 0.49 & 210 \\
R & & Magnetics & 2300 & 0.47 & 210 \\
P & & 2500 & 0.47 & 210 \\
F & & 3000 & 0.47 & 210 \\
M75 & & Ferroxcube & 5000 & 0.43 & 140 \\
A1 & & Magnetics & 40,000 & 1.58 & 500 \\
D1 & Tape wound core (nickel iron & & 100,000 & 0.82 & 460 \\
F1 & alloy) similar to amorphous & & 40,000 & 0.82 & 460 \\
A2 & & 40,000 & 1.58 & 500 \\
D2 & & 100,000 & 0.82 & 460 \\
F2 & & 40,000 & 0.82 & 460 \\
H2 & & 50,000 & 1.4 & 500 \\
F3M & & & 40,000 & 1.23 & 570 \\
Kool mu 26u & Powder & Hitachi & 26 & 1 & 500 \\
Kool mu 40u & & Magnetics & 40 & 1 & 500 \\
Kool mu 60u & & & 60 & 1 & 500 \\
Kool mu 90u & & & 125 & 1 & 500 \\
Kool mu 125u & & & 14 & 1 & 500 \\
MPP 14u & & & 200 & 0.75 & 460 \\
MPP 26u & & & 0.75 & 460 \\
MPP 125u & & & 0.75 & 460 \\
MPP 147u & & & 125 & 460 \\
MPP 200u & & & & 0.75 & 460 \\
\hline
\end{tabular}

Table 6 Availability of magnetic materials with respect to core shape

\begin{tabular}{lllll}
\hline & $\mathrm{E}$ & $\mathrm{ETD}$ & $\mathrm{U}$ & Toroid $\left(T_{\mathrm{c}}\right)$ \\
\hline Ferrite & $\mathrm{X}$ & $\mathrm{X}$ & $\mathrm{X}$ & $\mathrm{X}$ \\
Nano-crystalline & & & $\mathrm{X}^{\mathrm{a}}$ & $\mathrm{X}$ \\
Amorphous & & & $\mathrm{X}^{\mathrm{a}}$ & $\mathrm{X}$ \\
Powder & & & & $\mathrm{X}$ \\
\hline
\end{tabular}

${ }^{a}$ Materials not considered in this study because they are available with narrow volume range

Table 7 Volume range $\left(\mathrm{mm}^{3}\right)$ of magnetic cores for ferrite materials used in the discrete optimization [43-48]

\begin{tabular}{lcclll}
\hline Core & \multicolumn{2}{l}{ EPCOS ferrite materials } & & \multicolumn{2}{l}{ Magnetics ferrite materials } \\
\cline { 2 - 3 } \cline { 5 - 6 } & Smallest core & Biggest core & & Smallest core & Biggest core \\
\hline EE & 33 & 71,800 & & 78 & 72,300 \\
EI & & & & 1920 & 11,900 \\
ETD & 5350 & 51,200 & & 5470 & 51,500 \\
UU & 159,000 & 508,950 & & 350 & 199,000 \\
UI & 116,000 & 198,000 & & 283 & 158,000 \\
Toroid & 3 & 172,440 & & 4.3 & 161,086 \\
\hline
\end{tabular}

\section{References}

1. Billings KL (1989) Switchmode power supply handbook. McGraw-Hill, New York

2. Pressmann AI, Billings KL, Morey T (2009) Switchmode power supply design, 3rd edn. McGraw-Hill, New York

3. Maniktala S (2006) Switching power supplies A to Z. Elsevier, Amsterdam

4. Lenk R (2005) Practical design of power supplies. Wiley, New York

5. Brown M (1990) Practical switching power supply design. Academic Press, London

6. Kazimierczuk MK (2008) Pulse-width modulated DC-DC power converters. Wiley, New York

7. McLyman CT (2004) Transformer and inductor design handbook. Marcel Dekker, New York

8. Petkov R (1996) Optimum design of a high-power, high-frequency transformer. IEEE Trans Power Electron 11(1):33-42

9. Hurley WG, Wölfle WH, Breslin JG (1998) Optimized transformer design: inclusive of high-frequency effects. IEEE Trans Power Electron 13(4):651-659

10. Hurley WG, Wolfle WH (2013) Transformers and inductors for power electronics: theory, design and applications. Wiley, New York

11. Bosshard R, Kolar JW (2016) Comparative multi-objective optimization of $50 \mathrm{~kW} / 85 \mathrm{kHz}$ IPT system for public transport. IEEE J Emerg Sel Top Power Electron 4(4):1370-1382 
12. Muhlethaler J, Schweizer M, Blattmann R, Kolar JW, Ecklebe A (2013) Optimal design of LCL harmonic filters for three-phase PFC rectifiers. IEEE Trans Power Electron 28(7):3114-3125

13. Garcia-Bediaga A, Villar I, Rujas A, Mir L, Rufer A (2017) Multiobjective optimization of medium-frequency transformers for isolated soft-switching converters using a genetic algorithm. IEEE Trans Power Electron 32:2995-3006

14. Zou S, Lu J, Mallik A, Khaligh A (2018) Modeling and optimization of an integrated transformer for electric vehicle on-board charger applications. IEEE Trans Transp Electrif 4(2):355-363

15. Cassimere BN, Chan RR, Cale J, Cramer AM, Sudhoff SD (2007) Evolutionary design of electromagnetic and electromechanical devices. In: IEEE

16. Cale J, Sudhoff SD, Chan RR (2009) Ferrimagnetic inductor design using population-based design algorithms. IEEE Trans Power Electron 45(2):726-734

17. Sudhoff SD (2014) Power magnetic devices: a multi-objective design approach. Wiley-IEEE Press

18. Shane GM, Sudhoff SD (2013) Design paradigm for permanentmagnet-inductor-based power converters. IEEE Trans Energy Convers 28(4):880-893

19. Hilal A, Cougo B (2016) Optimal inductor design and material selection for high power density inverters used in aircraft applications. In: International conference on electrical systems for aircraft, railway, ship propulsion and road vehicles \& international transportation electrification conference (ESARS-ITEC)

20. Burkart RM, Kolar JW (2017) Comparative $\eta-\rho-\sigma$ Pareto optimization of $\mathrm{Si}$ and $\mathrm{SiC}$ multilevel dual-active-bridge topologies with wide input voltage range. IEEE Trans Power Electron 32(7):5258-5270

21. Andersen TM, Krismer F, Kolar JW, Toifl T, Menolfi C, Kull L, Morf T, Kossel M, Brändli M, Francese PA (2017) Modeling and Pareto optimization of on-chip switched capacitor converters. IEEE Trans Power Electron 32(1):363-377

22. Mejbri H, Ammous K, Abid S, Morel H, Ammous A (2014) Biobjective sizing optimization of power converter using genetic algorithms application to photovoltaic systems. Int J Comput Math Electr Electron Eng 33(1/2):398-422

23. Barg S, Ammous K, Mejbri H, Ammous A (2017) An improved empirical formulation for magnetic core losses estimation under nonsinusoidal induction. IEEE Trans Power Electron 32(3):2146-2154

24. Reinert J, Brockmeyer A, De Doncker RW (2001) Calculation of losses in ferro- and ferrimagnetic materials based on the modified Steinmetz equation. IEEE Trans Ind Appl 37(4):1055-1061

25. Li J, Abdallah T, Sullivan C (2001) Improved calculation of core loss with nonsinusoidal waveforms. In: IEEE industry applications society annual meeting, pp 2203-2210

26. Li J. Abdallah T, Sullivan C (2002) Accurate prediction of ferrite core loss with nonsinusoidal waveforms using only Steinmetz parameters. In: IEEE workshop on computers in power electronics

27. Mühlethaler J, Bielay J, Kolar JW, Ecklebez A (2012) Improved core loss calculation for magnetic components employed in power electronic systems. IEEE Trans Power Electron 27(2):964-973
28. Shen W, Wang F, Boroyevich D, Tipton C (2008) Loss characterization and calculation of nanocrystalline cores for highfrequency magnetics applications. IEEE Trans Power Electron 23(1):475-484

29. Dowell PL (1966) Effects of eddy currents in transformer windings. Proc IEEE 113(8):1387-1394

30. Ferreira JA (1994) Improved analytical modeling of conductive losses in magnetic components. IEEE Trans Power Electron 9(1):127-131

31. Nan X, Sullivan CR (2003) An improved calculation of proximityeffect loss in high-frequency windings of round conductors. In: IEEE

32. Nan X, Sullivan CR (2004) Simplified high-accuracy calculation of eddy-current losses in round-wire windings. In: IEEE power electron specialists conference

33. Erickson RW (2000) Fundamentals of power electronics. Colorado Power Electronics Center University of Colorado, Boulder Updated May 21

34. Maniktala S (2013) Switching power supply design and optimization (chapter 12). McGraw-Hill, New York

35. Microsemi (2013) Forward and flyback core selection using the LX7309 and industry recommendations, Technical Note

36. Texas Instruments, Magnetics design handbook: power transformer design, power.ti.com/seminars

37. Barg S, Alahdal A, Ammous K, Mejbri H, Ammous A (2016) Optimum design approach of high frequency transformer. In: Asia-Pacific international symposium on electromagnetic compatibility (APEMC)

38. Nanakos AC, Tatakis EC, Papanikolaou NP (2012) A weightedefficiency-oriented design methodology of flyback inverter for ac photovoltaic modules. IEEE Trans Power Electron 27(7):3221-3233

39. Texas Instruments, $120-\mathrm{V}$ AC, $200-\mathrm{W}, 90 \%$ efficiency, interleaved flyback for battery charging applications reference design. www. ti.com

40. ON Semicondcutor, $200 \mathrm{~W}$, Single Output Power Supply, www. onsemi.com

41. Vartak C, Abramovitz A, Smedley KM (2014) Analysis and design of energy regenerative snubber for transformer isolated converters. IEEE Trans Power Electron 29(11):6030-6040

42. Dimitrakakis GS, Tatakis EC (2009) High-frequency copper losses in magnetic components with layered windings. IEEE Trans Magn 45(8):3187-3199

43. Handbook of chemistry and physics, HCP, 58th edition, p F-163

44. Epcos data book 2013, Ferrite and accessories. www.epcos.com

45. Magnetics, Ferrite cores. www.mag-inc.com

46. Magnetics, Powder cores. www.mag-inc.com

47. Ferroxcube, Product selection guide 2013. www.ferroxcube.com

48. Finmet, EMC components

Publisher's Note Springer Nature remains neutral with regard to jurisdictional claims in published maps and institutional affiliations. 